\title{
Interaction between Fluid Urban Spaces and Reduction of Vulnerability to Risks and Threats in Urban Crises
}

\author{
Mostafa Bolourchi ${ }^{1} \&$ Maryam Bolourchi ${ }^{2}$ \\ ${ }^{1}$ CEO, Center for Interdisciplinary Research on Emerging Architectural Technologies (IREATech Center), \\ Rasht, Iran \\ ${ }^{2}$ Department of Architecture, Guilan University, Rasht, Iran \\ Correspondence: Mostafa Bolourchi, CEO, Center for Interdisciplinary Research on Emerging Architectural \\ Technologies (IREATech Center), Rasht, Iran. E-mail: mostafa.bolourchi@gmail.com
}

Received: October 26, 2016

doi:10.5539/jsd.v10n2p143
Accepted: December 6, $2016 \quad$ Online Published: March 30, 2017

URL: https://doi.org/10.5539/jsd.v10n2p143

\begin{abstract}
Tremendous technological developments in contemporary world have transformed all aspects of human life. Through interaction with these developments, living spaces should correspond to science and technology and serve to satisfy basic human needs especially safety and security. Due to their geographical and political situation, many countries have been exposed to a variety of natural or man-made threats, and have suffered heavy human and financial losses. For that reason, urban developments should make use of digital architecture products and create fluidity in order to modify human living spaces in correspondence with prerequisites of passive defense, for vulnerability reduction, and expansion of defensive measures in order to create an environment which holds the potential to overcome crises. The present research investigates the benefits of digital technology in formation of living spaces and the impact of approach to flexible urban spaces on mutual interaction between man and environment, as well as the extent to which these transformations create a sense of security and reduce vulnerabilities in urban crises. Fluidity of environment is in paradigm with active human responses to environment. The need for creating an environment safe from risks and threats is the motive behind the approach to flexibility with the use of technological advent. As a part of environment and by relying on computers and geometrical language, technology generates forms which are manifested in all parts and elements of living spaces, thus creating potential and elastic environments. It seems that by creating flexible spaces with the use of digital products, these environmental changes lead to organization of development plans, reduce vulnerability against natural risks and man-made threats, increase efficiency after said threat is realized, and significantly contain the extent and intensity of damages and losses.
\end{abstract}

Keywords: passive defense, fluidity, urban crises, digital architecture, flexibility, elasticity

\section{Introduction}

Under the influence of rapid scientific and technological advent and urban developments, contemporary architecture has recognized new needs in society which demand new ideas and solutions in urban management and planning. Perhaps we have to think again; and as Schopenhauer says, this thought might reflect upon the reality which is in front of our eyes, yet nobody has seen it. However, in alignment with other societies and global trends, new needs are on the rise. Today's architecture should be able to keep up with these needs and exhibit its corresponding formal and spatial characteristics. According to Charles Jencks, in today's world, architecture should be affected by man's view of himself and his surrounding world. Today's architecture should be the outcome of today's conditions, affected by science, technology, and contemporary philosophy (Ghobadian, 2005). Architecture should correspond to resulted advents and serve to satisfy basic human needs especially safety and security. Due to their geographical and political situation, many countries have been exposed to a variety of natural disasters and threats. According to statistics released by international organizations, natural disasters have posed greater threats than any man-made dangers in the past decade. Therefore, development plans will consider regulations and design requirement and incorporate preventive measures to reduce the impact of natural disasters such as earthquakes, floods, droughts, and etc., as well as other threats such as explosions. Such purposeful plans can greatly reduce human's vulnerability against these crises; along with fortification of existing urban structures and overlooking the developments which would decrease flexibility, measures could be 
taken to increase efficiency after urban crises occur.

Through library and field study, and with the use of questionnaire, the present research investigates the benefits of solely parametric digital technology in formation of living spaces and the impact of approach to flexible urban spaces on mutual interaction between man and environment, as well as the extent to which these transformations create a sense of security in urban environments (potentially new environments) and reduce vulnerabilities in urban crises. Therefore, in terms of type and method of data collection, the present research is a descriptive-survey study. Yet, no similar case study has been found which covers all objectives which are being followed in this research. It is obvious that some studies have been conducted based on standpoints and frameworks which might correspond to parts of the present research. However, the triple axes of the present research are as follows:

1) The impact of designing urban facilities using digital products based on prerequisites of passive defense on reduction of vulnerability against urban crises as well as increase of efficiency after crises

2) The impact of digital architectural products on formation of living spaces, and approach to elastic urban environment (space) affected by contemporary scientific and technological advents

3) The impact of potentially new (urban) environment (space) on people's feeling of security.

In order to elaborate on these axes and frameworks, the first chapter comprises a set of definitions and principles which explain the compatibility of human and built (artificial) environment; the second chapter briefly discusses the need for safety, security, sense of environmental security, and components which contribute to that; the third chapter explains requirement of passive defense in urban design and architectural forms suitable for confrontation with risks and threats; the fourth chapter involves flexibility and its related issues; the fifth chapter deals with digital architecture products and their impact on formation of human living spaces while explaining self-organizing patterns and models; the sixth chapter explains and analyses research findings; in the final chapter, obtained results and findings are summarized. The present research reveals that by creating flexible and fluid spaces, environmental changes enhance the sense of environmental security, reduce vulnerability against natural risks and man-made threats, increase efficiency after threats are realized, and reduce the extent and intensity of damages and losses caused by unforeseen incidents.

\section{Definitions}

\subsection{Built (Artificial) Environment}

Built space is a part of human living space. It is a set of adaptations between man and environment which enables human activities to be more responsive to their objectives. If formed appropriately, built space can satisfy some aspects of human needs (Lang, 2007).

\subsection{Sense}

The transfer of the stimuli effect through neural receptors to central nervous system which can be tangibly followed is called feeling or sense. This feeling takes place in two stages: internal or external stimulation and effect on the sensory organ. This process starts from one of sense; then it is transformed from nerves tissues to spinal cord and central nervous system, thus creating a sense or feeling. In cognitive psychology which is associated with mental qualities and mechanisms, sensory cognition is the prerequisite for any type of activity (Irvani \& Khodapanahi, 2011).

\subsection{Perception (Environmental)}

Perception is a process which is located at the center of any environmental behavior. Environment is the source of all information; therefore it is not similar to sense. It is rather the results of a person's processing by means of his own cognitive experience. In fact, as a part of observed environment, an individual plays an important part in determining the boundaries and other characteristics of environment by his movement and behavior in a space. Space is considered to be a personal experience which is the result of an individual's cognitive process as he assigns meaning to the whole, parts, and the relationship between parts (Barati \& Soleiman Nejad, 2011). In this sense, perception is the point where cognition and reality meet (Lang, 2007).

\subsection{Action}

It is the active and creative response of an actor or agent (human) to his surrounding built environment; it is nothing but the actor's effort to adapt to the norms. On that basis, Parsons defines four components for a unit act of action:

1) It requires a human actor or agent. 
2) It requires an end toward which action is oriented and means to reach this end.

3) It requires a situation where the actor is present; it is comprised of uncontrollable elements (means) and controllable elements (conditions).

4) In order to choose means to achieve ends, the actor uses norms and values (Parsons, 1937).

\subsection{Threats}

In order to design safe spaces in the time of crisis, type of threats should be identified (Faraji \& Akbari Afkhami, 2010). On that basis, by nature, threats are classified into three categories which are:

1) Military threats, including air strikes, land or marine offensives, terrorist attacks, or security threats.

2) Natural threats, including disasters such as earthquake, floods, storms, and etc.

3) Industrial threats, which include all sorts of threats posed by destructive industrial accidents such as chemical leakage, nuclear radiation, and etc. (office of national construction regulation, 2012).

\subsection{Crisis}

Due to disagreement between experts, definition of crisis is not an easy task. Yet it seems that this term has found its way from medicine to social and economic sciences. In medicine, critical condition is one in which the body of a living creature falls into disorder and danger. Therefore, some believe that in regard to social issues, when the society deviates from normal order and falls into distress, the critical condition emerges. In the end and considering these descriptions, crisis can be defined as follows: crisis is an abnormal situation where abrupt and unforeseen problems take place; in a situation like this, customary norms, rules, and regulation will no more be effective (Ahadnejad et al, 2012).

\subsection{Human Needs}

According to Maslow, human needs have a hierarchy and in some moments, human behavior is heavily affected by these needs. As needs are satisfied, a person's view changes and another level of needs replace the old ones and drive his behavior. Needs continue to rise until the top of the hierarchy, and after being satisfied, they give way to other needs. In this theory, human needs are classified in five categories which respectively are: physiological, safety (security), social needs (love and belonging), esteem, and self-actualization. Some needs have physiological basis, some have social basis, and some are a mixture. However, most fundamental needs have a physiological basis (Lang, 2007). It is evident that people pay attention to capacities of environment based on their needs; therefore, general public's view of an environment mostly depends on the satisfaction of their needs.

\section{Safety Need}

After physiological needs, safety (security) needs are considered to be the most important (Lang, 2007). These needs are intensely and closely related to environment's social and physical characteristics (Gharaei et al, 2010). From the psychological point of view, these needs represent human's desire for intimate peace, mental comfort, and avoidance of disorder and distress. Such characteristics are perceived from active components of environment and after being mentally processed, they create a sense of safety and security (Bemanian \& Mahmoudinejad, 2008). In response to human needs, these features provide a level of comfort.

\subsection{Security and Urban Environment}

Nowadays, security is a qualitative index of urban life (Gharaei et al, 2010). It has distinct dimensions which are derived from social, cultural, economic, political, and religious concepts of urban structure (Bemanian \& Mahmoudinejad, 2008). Human security is an important concept which refers to protection of personal, financial, cultural, social, and political rights. Human security has two aspects: the minimal aspect (adequacy) where all individuals are able to finance their lives and secure their survival and safety, and improved dimension (welfare) wherein people are able to have positive feelings and wellbeing in life while enjoying psycho-social security (Barati et al, 2013).

\subsubsection{Environmental Security}

Environmental security refers to the safety of citizen and their perception of being safe from natural disasters such as earthquakes, floods, and etc. The role of urban structure, standards (in urban construction), and security protocols of urban design contribute to this perception (Bemanian \& Mahmoudinejad, 2008).

\subsubsection{Sense of Security}

Security and safety have concrete and abstract aspects. Concrete aspect is based on statistics, and abstract aspect 
which is known as "sense of security" is affected by psychological factors. This sense (of security) is realized when the individual has a mental perception of a situation which is created by a distinct urban and cultural structure. On that basis, from psychological standpoint, sense of security depends on urban environment, actions, and incidents on one hand, and interpretation and level of perceptions in a certain cultural frame on the other (Bemanian \& Mahmoudinejad, 2008).

\subsubsection{Indices of Urban Design Contributing to Urban Security}

Urban indices are defined as follows: statistics, statistical series, or other empirical evidence which enable us evaluate current and future conditions based on our goals and values so that we could assess plans and programs in order to determine their impacts. Design indices contributing to urban security are a below:

1) Physical (location): physical indices contributing to public (urban) space security are mutually effective. Through social-cultural relations, man gives significance to space, form, and performance. Organization of space will subsequently change the shape of these relations.

2) Readability: by means of physical instruments, a city becomes more evident and clear. Depending on the extent to which physical space can symbolically communicate to the citizens, a city is evaluated to be either readable or unreadable.

3) Accessibility: accessibility is an important criterion for assessment of safety and security in cities. Access to transportation and movement across the city based on transportation standards may reduce or increase stress levels in citizens.

4) Openness of space: humans focus their effort to overcome and live in any environment in order to achieve peace and comfort. However, today and in large scales, there is no such sense of control and overcome; there is rather a separation and scattering between spaces and man's mentality. As a result, the feeling of belonging to space and location is vanished.

5) Livelihood: livelihood and dynamism of urban spaces or their dullness reflect the extent and type of activities taking place in those spaces. Therefore, a lively urban space refers to an environment where a considerable number of individuals with high diversity (in terms of age and sex) are willingly and socially active for a large span of time every day.

6) Diversity: taking the demands of various age groups into consideration and paying attention to accessibility, security, peace, and spatial movement of people with disability create diversity within urban space. Every group finds a place in the city and relates with urban life and space.

7) Homogeneity: if the types of use which overlap one another are more consistent and homogeneous, citizens will be more at ease. A significant amount of visual distortion in urban space will directly increase fear and stress in residents and lead to insecurity.

8) Environmental safety and health: inappropriate urban design leads to formation of locations which are vulnerable in terms of environmental characteristics, and as a result are more prone to crime and delinquency.

9) Transportation: preservation of city's security is the main goal of streets and sidewalks in that city.

10) Urban furniture: suitable urban furniture is one of the factors contributing to presence of pedestrians and subsequently further interaction between people in environment which leads to citizens' mental health and peace of mind (Barati et al, 2013).

\section{Passive Defense}

Passive defense refers to a set of tactical measures taken which increase preventive force, reduce vulnerability, improve national sustainability, sustains necessary activities, and facilitates crisis management against threats or enemy's military offensive (office of national construction regulation, 2012). Dr. Asgharian Jeddi considers the "human factor" to be the distinction between passive and active defense. In this sense, active defense is a measure which requires direct management and use by humans and includes military equipment, organization, training, and management of human forces without which the instruments and equipment would be useless. On the other hand, passive defense refers to architectural facilities for war engineering which increase the defensive capabilities of armed forces (Nezam Kheirabadi, 2012). Therefore, passive defense is considered to be the most sustainable, cost-efficient, and peaceful method of defense against enemy offensive and destructive measures as well as natural disasters. Therefore, it is the most suitable method to reduce risks and vulnerability of human resources, buildings, facilities, equipment, documents, and routes in the country (Bagheri \& Sobhani, 2010). 


\subsection{Requirements of Urban Design}

As mediators, architecture and urban design enhance the defensive power. Satisfaction of safety needs in Maslow's hierarchy of needs leaves a positive effect and leads to human survival (Faraji \& Akbari Afkhami, 2010). Considering the importance and wide application of this subject in countries which are involved in prevention and reduction of damages caused by war and crises such as earthquake and other natural disasters, the use of passive defense methods in urban design would be extremely effective in achievement of a desirable urban view which also supports the minimums for passive defense. Considering this issue, the requirements of urban planning in order to accomplish designs corresponding to passive defense are as below:

1) Site selection and location of wide and open urban spaces

2) Making urban spaces multi-tasked and multi-purposed

3) Entrances and exits (urban arteries)

4) Camouflage and sealing (from formal design standpoint)

5) Distribution of important spaces

6) Urban furniture and green spaces (Sharaki Moghadam \& Kiani, 2013).

\subsubsection{Requirements of Formal Design in Passive Defense}

As we know, the form of building has a great impact on the general damages inflicted on the structure. Therefore, regarding explosion and its impact on the form and volume of building, it can be said that horizontally laid out form at the first level, and forms with equal proportions at the second level are more stable and resistant than vertically standing forms. Increased height and tall forms increase the vulnerability against explosions. Also, in order for explosion wave to pass through buildings, soft and aerodynamic forms can be used since the damages would be considerably less than geometrical and non-aerodynamic forms (Mirhashemi Routeh, 2011). However, the total volume and form of building has an important effect in stability and explosion impacts. Another factor which can reduce explosion impact is the use of full and empty spaces. In that case, the main form of building should be able to prevent the intensification of explosion wave in one point of the structure. There are two very important notes in designing forms resistant to man-made threats:

1) Convex forms are always preferred to concave forms.

2) More aerodynamic building structures (round and oval shapes) can withstand explosion waves more easily (Mirhashemi Routeh, 2011).

\section{Flexibility in Architecture}

In Dehkhoda Dictionary, elastic is defined as something which bends and returns to its original form. Its literal definition is the ability to change easily (Mahdavinejad et al, 2011). According to definitions, flexibility is the ability to change easily and return to original state. The same definition is also used in architecture. The purpose of flexibility in built environment is to make it possible for spaces to change in accordance with the changes in their performance (Grouter, 2007). Therefore, both theory and practice (numerous experiences in the history of architecture) prove the necessity of flexibility. From theoretical standpoint, constant changes which happen on a daily, monthly, or annual basis in human environment can be classified into three categories:

1) Changes in demographic structure

2) Changes in regulations and standards

3) Changes in values

In order to adapt to these changes and maintain the quality of spaces, architecture is forced to change, a kind of change which is considered to be flexibility. From the practical standpoint, there are numerous instances in architectural history where certain building uses had to change after a while in order to respond to new situations (Mahdavinejad et al, 2011).

\section{Technology}

As a part of environment, technology is derived from the Greek word "technologica", meaning systematic behavior. In early $18^{\text {th }}$ century, technology defined arts, and in mid $19^{\text {th }}$ century it referred to experimental arts (Sharoudi \& Golabchi, 2007). However, technology has different connotations for philosophers. Hart Davidson defines technology as a set of artifacts, cultural beliefs, experiences, and backgrounds which encompass production; it include consumption, distribution, and design of these artifacts for production in certain cultural situations (Shahroudi \& Golabchi, 2007). However, Martin Heidegger believes that technology is a type of 
instrument and human activity; its general concept could be an instrumental and anthropological definition of technology (Heidegger, 1999). Yet, according to Jaspers, art and technique is a means, and technique uses this means in order to accomplish and end (Sharoudi \& Golabchi, 2007).

\subsection{Digital Architecture Products}

Nowadays, architects tend to create fluid and complex computer-generated forms which have been made possible by digital technological advents. The concept of this modern (digital) architecture relies on the use of computer in an experimental perspective (Picon, 2012). Without a doubt, traditional methods and instruments can not respond to needs of this architecture, because digital architecture demands new and specific instruments in order to be realized. Digital construction is possible by putting architecture and construction machinery together. Therefore, one of the issues in digital architecture is the attention to construction parameters from the beginning of design process and incorporating these controlling parameters in design algorithms in a way that the final product has the capacity to be constructed. In fact, designed form can be affected from the very beginning by construction factors so that any movement, curves, or turns which make the construction difficult is omitted and the final form is constructed based on these criteria (Khabazi, 2011).

\subsubsection{Parametric Architecture}

Parametricism is a new concept in architecture which makes it possible to achieve fluidity in all stages and scales, from preliminary sketches to construction, and from single buildings to large urban compositions (Schumacher, 2009). In this approach, the form is automatically produced in computer environment and based on the available data; shapes are in fact a response to primary criteria. They are shaped based on one or several certain criteria. The final forms correspond to changes in those criteria (Khabazi, 2011) in order to meet the needs of society by means of numerous parametric designs (Schumacher, 2009). Patrick Schumacher, the contemporary architecture theorist considers this trend as a new architectural style called "parametric architecture" (Khabazi, 2011) which offers great diversity in construction industry and a new attitude toward architecture.

\subsubsection{Formation of Space}

Parametric design or the grammar of geometrical shapes is a new branch in computerized sciences, which seeks to discover and utilize logical and mathematical relationship between numbers and digits on one hand and shapes on the other. By discovering this relationship, the language and grammar of the relationship between shapes and digital world is defined. The purpose of grammatical expression of shapes is to generate geometrical shapes using which unprecedented forms can be produced by computer. In fact, in this style the user only creates formulae, and the computer uses those formulae to generate forms. Parametric shapes grammar is an advanced form of shapes grammar which has one or more numerical parameters in its formulation; by changing those parameters, the formula provides different outputs. In other words, with the use of parametric design, one can expect creativity and innovation from the computer and achieve forms which have never been on paper or even in our mind but can be used in different parts of architecture. Therefore, use of modeling techniques based on parametric diversity allows the user to design a system rather than a model (Golabchi et al, 2012) which can respond to its surrounding environment. Parametric architecture has tried to adapt to the environment; for that purpose and with the use of new techniques and instruments, it is able to extract qualities and characteristics of complex natural systems and incorporate them into architectural projects and designs (Khabazi, 2011) as demonstrated in Figure 1. 


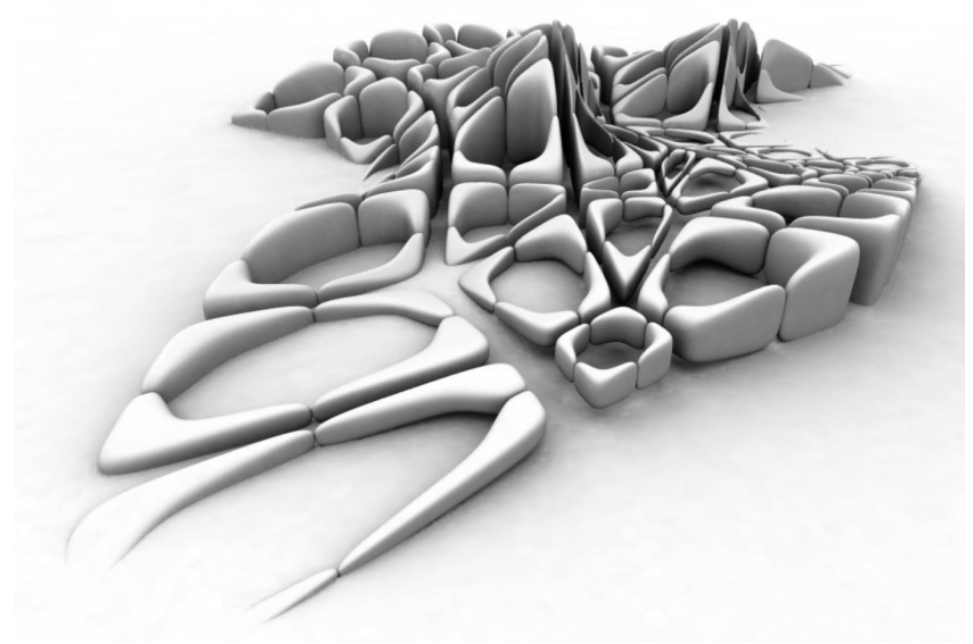

Figure 1. Comprehensive design of Kartal Pendik in Istanbul, Zaha Hadid architecture office

Source: zaha-hadid.com

In the process of parametric design, the role of algorithms as the main factors on creation of architectural space is significant. An algorithm is a set of predefined and step-by-step rules in a hierarchy which can perform a certain operation. Algorithms are used for calculations, data processing, and logical decision-making. These algorithms carry out an operation step-by-step. They are important because they can script the method of work and provide a common rule for working methods. By coding the algorithms using computer programming languages, the high calculating power of computers can be utilized for fast and accurate calculation and anticipation of complex operations. Therefore, in designing spaces, many designing activities can be compiled into algorithms and put in computers in order to accomplish the final products; the products of design algorithms are forms and volumes (Khabazi, 2011). Considering the ability of parametric design which employs ordered, systematic, and modular rules, a form can be associated with other forms of one family. By manipulating a parameter through algorithms, different formal characteristics can be assigned to space; soft forms and volumes and fluid lines are the distinctive characteristics of this type of architecture (Khabazi, 2011).

\section{Research Findings}

Considering the wide application of digital products and prerequisites of passive defense in urban design in order to reduce damages and losses, and regarding the fact that the existing facilities have not been able to withstand various threats, but have rather been used as shelters in the time of crisis, the question which always arises is: how and using which plans could a city become immune to unpredictable threats and incidents? Can forming and shaping cities based on requirements of passive defense reduce the damages? Can the users of changed spaces still connect with newly formed spaces? And, can these spaces support the mental security of citizens?

Among all components, urban forms play an important part in reducing the damages and losses caused by unpredicted incidents. As we know, the form of building has a great impact on the general damages inflicted on the structure. Therefore, regarding explosion and its impact on the form and volume of building, it can be said that horizontally laid out form at the first level, and forms with equal proportions at the second level are more stable and resistant than vertically standing forms. Also, in order for explosion wave to pass through buildings, soft and aerodynamic forms can be used since the damages would be considerably less than geometrical and non-aerodynamic forms (Mirhashemi Routeh, 2011). However, the total volume and form of building has an important effect in stability and explosion impacts. That is because form as an architectural expression is the explicit manifestation of an object (Grouter, 2007). In the first glance, (without considering the scales) computer-generated form might seem very complicated. However, despite their geometrical complexity, they are very perceivable for the viewer due to their naturally inspired origins. Freud considers the stream of consciousness to be originated from human unconscious, and Yung believes that the unconscious has signs of past (patterns). Therefore, parametrically generated form carry within them criteria from the past which can be perceived by the viewer; since they are originated from the stream of consciousness, they break the bounds of time. In a philosophical way, they are inspired by non-linear basis and their fluidity comes from parametric 
(algorithmic) design. These forms are at the same time very resistant and strong. Based on geometric logic, these forms are inspired by nature; therefore they contain the requirements of passive defense: oval and convex forms with suitable aerodynamic structure which can withstand explosion waves (Bagheri \& Sobhani, 2010), and are less vulnerable to primary and secondary shrapnel. Consistent membrane (in this style) can be used in surfaces exposed to explosion or earthquake in order to prevent the collapse of building materials. In some major urban projects such as the comprehensive design of Istanbul or Singapore by Zaha Hadid architecture office, we see the use of mass organizing and spatial deployment where building blocks and open spaces are adjacent to each other and relate to one another in different ways. The factor which integrates the elements in mass organization is a shared feature such as a performance, a form, an axis, and etc. However, different form and performance can lead to mass organizing if there is a visual order or another similar factor (Bagheri \& Sobhani, 2010). Despite its complexity, the results originated from natural patterns have a spatial consistency which improves the efficiency in the time of crisis. Naturally, creative and innovative solutions as presented in figure 2 can also be a complementary to these designs.

The gradual evolution of digital architecture and urban design in the past decade has paved the way for brave new ideas such as the future urban design by BIG architecture firm. This design mingles sidewalks and streets in a way that they establish a completely elastic environment and change their performance in accordance with human needs. In explanation of the performance of flexible systems, Bjarke Ingels the founder of BIG architecture firm states that Our roads could serve as a programmable surface so that by switching say a light on and off you can change a street into a plaza, or instantly materialize a sports court, or dynamically expand and contract to create more or less bicycle space, pedestrian space, or car space in a way that has not been possible.
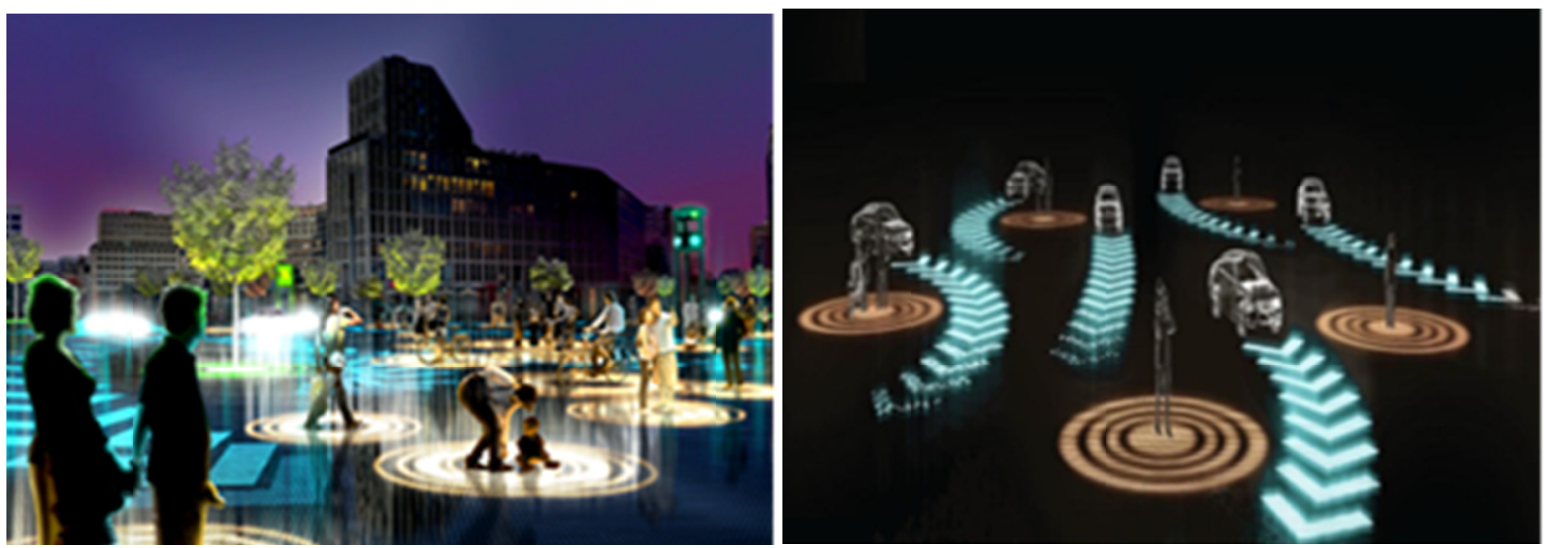

Figure 2. Computer simulation of future urban design by BIG firm, for Audi automotive industry

Source: big.dk

However, despite adventurous ideas in digital arena, one should not merely rely on features of parametric design and self-organizing models, but rather study the psychological impacts of such spaces on creating a sense of security in mankind. In order to achieve this goal, it should be investigated whether man as an actor can establish a close relationship with such intense changes in urban structure. To answer that, students are architecture have been asked about the impact of potentially new environment on sense of security and effective urban indices in urban safety, in order to assess the impact of such changes on feeling of safety. According to Porteous, among four senses engaged in environment i.e. vision, hearing, smell, and touch, vision is the most fundamental one; it receives most information from the environment and transmits it to the brain. Therefore, he considers vision to be an active, intuitive, and complex sense (Barati \& Soleimannejad, 2011) using which distance, color, shape, texture, and contrast in an environment are perceived. On that basis, the present research aims to study the impact of digital products on formation of human living environment, and approach to an elastic, elastic urban environment contributing to sense of security in human as an agent. In order to evaluate that, a questionnaire comprised of 20 items and 4 pictures (pictures 3 to 6 ) is designed along with a brief explanation in this regard. Considering the intense complexity of this issue for general public, 30 students from faculty of architecture of Islamic Azad University (Kish international branch) are selected. To facilitate the research process, the participants are divided into three groups of ten, and tested in order to assess the sense of security in potentially new environments. Therefore, questionnaires comprised of 20 questions about 7 subscales examining indices of urban design affecting urban security have been distributed among participants. After extensive preliminary explanations regarding digital environments and their impact on surrounding spaces, participants are asked to 
refer to their understanding of the subject, and evaluate 4 pictures of potential urban environments which demonstrate elasticity and fluidity, and provide their point of view by choosing an alternative answer between 1 and 5. The results and responses are presented in table 1.

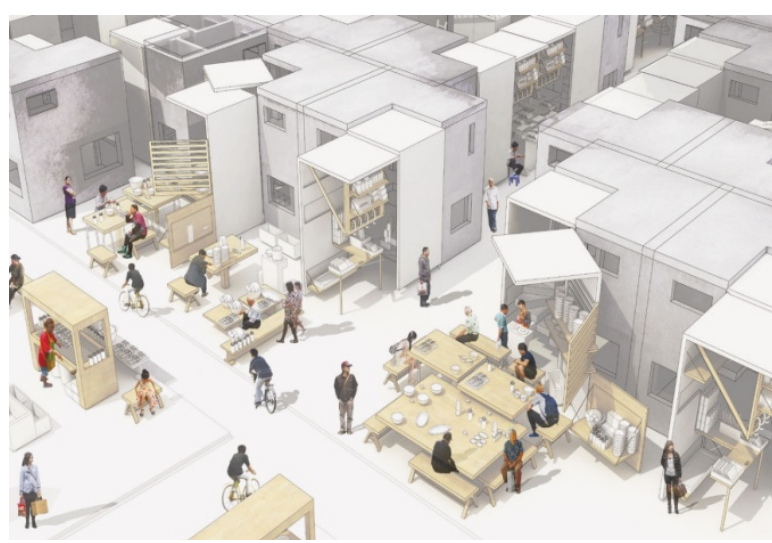

Figure 3. Flexible urban texture source: aaschool.ac.uk

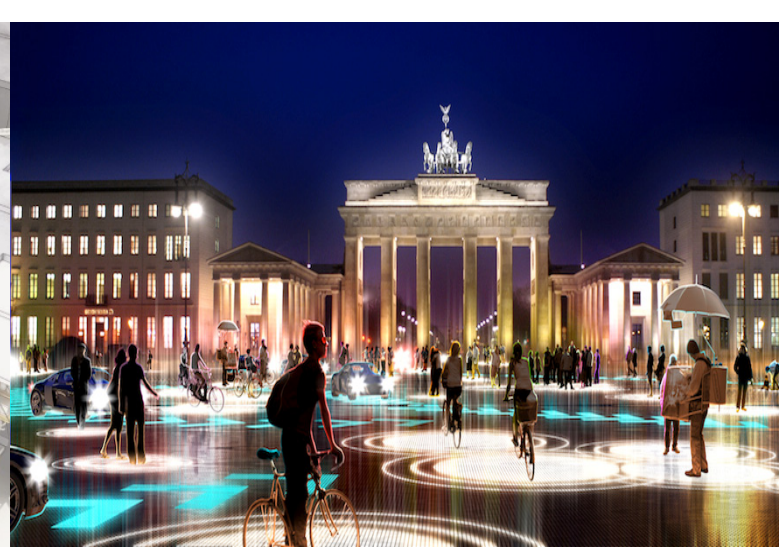

Figure 4. Future urban design source: big.dk

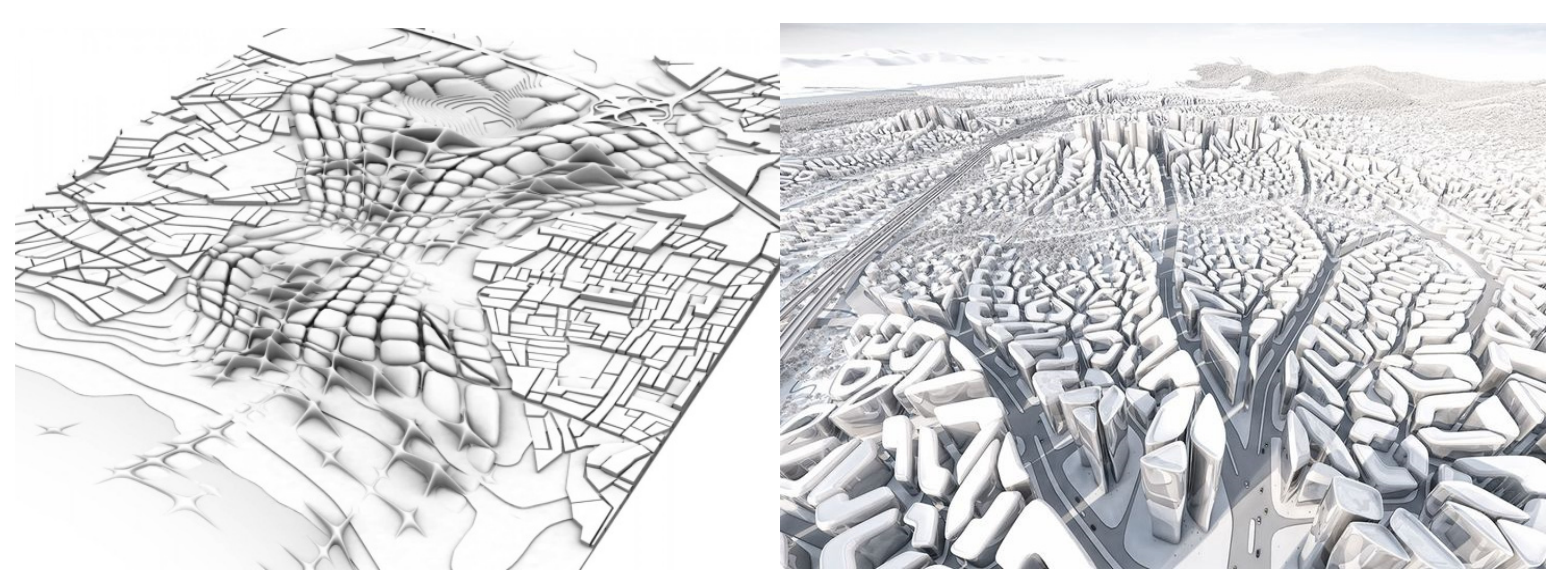

Figure 5. Kartal-Pendik comprehensive design source: zaha-hadid.com

Figure 6. parametric urban design source: patrikschumacher.com 
Table 1. Survey results; source: author (2014)

\begin{tabular}{|c|c|c|c|c|c|c|c|}
\hline & \multirow{2}{*}{ Affecting factors } & \multicolumn{2}{|c|}{ Neutral } & \multicolumn{2}{|c|}{ Unsatisfied } & \multicolumn{2}{|c|}{ Satisfied } \\
\hline & & Number & Percent & Number & Percent & Number & Percent \\
\hline \multirow{6}{*}{ Fabric } & Harmony and desirability & 4 & 13.3 & 0 & 6.6 & 24 & 80 \\
\hline & Buildings' shape and form & 0 & - & 6 & 20 & 24 & 80 \\
\hline & Buildings' visual attraction & 0 & - & 7 & 23.3 & 23 & 76.6 \\
\hline & Density of texture & 9 & 30 & 13 & 43.3 & 8 & 26.6 \\
\hline & Full \& empty spaces & 1 & 3.3 & 3 & 10 & 26 & 86.6 \\
\hline & Street patterns & 15 & 50 & 8 & 26.6 & 7 & 23.3 \\
\hline \multirow{3}{*}{ Readability } & Predictability of streets & 0 & - & 11 & 36.6 & 19 & 63.3 \\
\hline & $\begin{array}{l}\text { Visual connection with } \\
\text { surrounding areas }\end{array}$ & 3 & 10 & 4 & 13.3 & 23 & 76.6 \\
\hline & Clarity of street patterns & 2 & 6.6 & 6 & 20 & 24 & 80 \\
\hline \multirow[b]{2}{*}{ Accessibility } & $\begin{array}{l}\text { Ease of passage and } \\
\text { transportation }\end{array}$ & 0 & - & 9 & 30 & 21 & 70 \\
\hline & $\begin{array}{l}\text { Separation of means of } \\
\text { transportation } \\
\text { ((non-interference }\end{array}$ & 2 & 6.6 & 2 & 6.6 & 26 & 86.6 \\
\hline \multirow{3}{*}{$\begin{array}{l}\text { Openness of } \\
\text { space }\end{array}$} & Adequate public space & 0 & - & 7 & 23.3 & 23 & 76.6 \\
\hline & $\begin{array}{l}\text { Participation in use of public } \\
\text { spaces }\end{array}$ & 3 & 10 & 7 & 23.3 & 20 & 66.6 \\
\hline & Freedom of movement & 0 & - & 11 & 36.6 & 19 & 63.3 \\
\hline Livelihood & $\begin{array}{c}\text { Sense of livelihood and } \\
\text { excitement in urban spaces }\end{array}$ & 2 & 6.6 & 1 & 3.3 & 27 & 90 \\
\hline \multirow{3}{*}{ Diversity } & Diversity of open spaces & 7 & 23.3 & 7 & 23.3 & 16 & 53.3 \\
\hline & Combination of uses & 9 & 30 & 5 & 16.6 & 16 & 53.3 \\
\hline & $\begin{array}{l}\text { Diversity in transportation } \\
\text { network }\end{array}$ & 3 & 10 & 7 & 23.3 & 20 & 66.6 \\
\hline \multirow[t]{2}{*}{ Homogeneity } & $\begin{array}{l}\text { Compatibility and consistency } \\
\text { of uses }\end{array}$ & 6 & 20 & 11 & 36.6 & 13 & 43.3 \\
\hline & Visual distortion & 1 & 3.3 & 14 & 46.6 & 15 & 50 \\
\hline
\end{tabular}

It must be noted that there are more variables contributing to reduction or increase of sense of security; however, regarding the small scale of digital architecture works (specially parametric design and self-organizing models) and considering the fact that they are mostly constructed at laboratorial scale, the present study focuses only on the most effective variables which are associated with the impact of environmental (spatial) changes on citizens' sense of security. In any event, it seems that the participants have been more satisfied with new urban spaces (which are mostly concepts or developed in experimental studies) as compared to present urban spaces. It is natural that this satisfaction increases mental peace and releases the citizens from anxiety, they will have more psychosocial security, and their welfare would also improve. According to the participants, presence in new spaces would not cause fear; despite the expectations, these new spaces would not diminish peace and comfort. Since this questionnaire has been answered by a group of architecture students, therefore most participants have been sure of the sustainability of these urban complexes and consider the forms of urban facilities (as presented in pictures) to be more resistant against earthquake and explosions. 


\section{Conclusion}

The influential impacts of contemporary science and technology are visible in all layers of life. Without a doubt, digital architecture as an instance of these scientific and technological advents will lead to tremendous changes in the process of design and construction. According to Patrick Schumacher, digital architecture (specifically parametric) has brought forth a new meaning to architecture and has made it possible to achieve fluidity across all scales. If this fluidity is linked with the structure of our surrounding nature, we can achieve qualities which natural process has bestowed upon organisms in form, performance, and behavior and accomplish self-organizing forms (models). Nature is full of such self-organizing models and algorithmic instruments have the ability to produce and program self-organizing systems to some extent (in small lab scales). These natural forms have better performance against unpredicted incidents. If natural models are implemented in major urban scales, better performance against threats would be accomplished because the structure of these forms has the flexibility and fluidity which can also be observed in nature. Also, since these forms are originated from nature, human can establish a close relationship with them. Since man's behavior is flexible, he can survive only by adapting to the life environment (Lang, 1998). Flexibility caused by the change of urban spaces will increase the feeling of safety in the viewer. Flexible and fluid spaces offer the users further choices. In comparison with a limited and one-dimensional space, these spaces are able to respond to different needs and conditions. Therefore, the efficiency of environment in confrontation with unpredicted accidents will increase. Yet, despite the numerous advantages of digital design and construction, there are many obstacles before the process of development in our country which cast a shadow on all areas i.e. economic, cultural, and etc. Also in international scale, these limitations have left their impacts in other ways and have confined digital solutions to small scales (mostly in the form of experimental lab projects). But it is obvious that in future decades, the prevalent paradigm would be the approach to complete compatibility with environment in all levels, and discovery of the relationships governing biological, formal, geometrical, and natural entities, as well as the behavior of these organisms in different scales (Khabazi, 2011) in order to respond to future urban crises and provide more effective global solutions by mastering the process of algorithmic creation (Khabazi, 2011) which reduces vulnerability, increases sustainability, ad enhances the defensive power of cities in critical conditions. Judging by the opinions of the participants, it seems that the participants have been more satisfied with new urban spaces (which are mostly concepts or developed in experimental studies) as compared to present urban spaces. It is natural that this satisfaction increases mental peace and releases the citizens from anxiety, and they will have more psychosocial security. Subsequently, this can increase the efficiency of crisis management in the time of crisis.

\section{References}

Ahadinejad, M., Alipour, S., \& Alipour, S. (2012). Crisis and urban management performance, $1^{\text {st }}$ national conference of urban crisis in 1404 horizon plan, Abhar, 2012.

Baghri, V., \& Sobhani, A. (2010). principles of passive defense in architectural design with an approach to Azerbaijan native architecture (Kandovan Village), $1^{\text {st }}$ conference of passive defense and resistant structures, Babol, March 2010.

Barati, N., \& Soleimannejad, M. A. (2011). Perception of stimulants in controlled environment and the impact of gender on it; case study: students of faculty of architecture and urban design in Imam Khmoeini International University, Bagh-Nazar scientific-research periodical, Vol.8, No.17, pp:19-30.

Barati, N., Ahar, H., Manouchehri, A., Gheisari, H., \& Shamsollahzadeh, Y. (2013). evaluation of urban safety and security using indices of environmental design and quality, case study: Maragheh City, $1^{\text {st }}$ conference of architecture and urban design in the passage of time, Qazvin, April $20^{\text {th }}$.

Bemanian, M. R., \& Mahmoudinejad, H. (2008). Evaluation of factors affecting urban sense of security, case study: Kerman City. Urban management periodical, 19, 59-71.

Faradji, A., \& Akbari Afkhami, D. (2010). passive defense and architectural observations, $1^{\text {st }}$ conference of passive defense and resistant structures, Babol, March 2010.

Gharaei, F., Rad Jahanbazi, N., \& Rashipour, N. (2010). study and assessment of sense of security in urban areas, case study: district 2 and 11 od Tehran, Armanshahr, No.4, PP:33-71.

Ghobadian, V. (2005). principles and concepts in contemporary Western architecture (3rd ed.). Tehran, office of cultural studies.

Golabchi, M. (2012). Andaji Garmaroudi A, Bastani H, 2012, digital architecture, $1^{\text {st }}$ edition, Tehran University Press. 
Grouter, Y. K. (2007). aesthetics in architecture, translated by Pakzad J, Homayoun A, $4^{\text {th }}$ edition, Tehran, Shahid Beheshti University Press.

Heidegger, M. (1998). a question about technology, translated by Asadi M.A, $1^{\text {st }}$ edition, contemporary knowledge and though cultural institute.

Irvani, M., \& Khodapanahi, M. K. (2011). psychology and sense and perception (2nd revision), $15^{\text {th }}$ edition, Tehran, The organization for researching and composing university textbooks in the humanities (SAMT).

Khabazi, Z. (2011). Algorithmic architecture paradigm (1st ed.). Ketabkade Kasra publication.

Lang, J. (2007). creation of architecture theory: role of behavioral science in environmental design, translated by Eynifar A, $3^{\text {rd }}$ edition, Tehran, Tehran University Press.

Mahdavinejad, M. J., Farajollahi Rad, A., \& Karam, A. (2011). flexible and elastic architecture, an approach to harmony of architecture and structure, $2^{\text {nd }}$ international conference of architecture and structure, Tehran, May 2011.

Mirhashemi Roueth, A. (2011). requirements of passive defense architecture, solutions for designing fortified buildings, $4^{\text {th }}$ national conference of construction (fortification and preservation of lasting buildings), Arak, September $4^{\text {th }} \& 6^{\text {th }}$.

Nezam Kheirabadi, A. (2012). explosion and the effect of building's forms on reduction of explosion impact, national conference of construction and sustainable development, Mashhad, December $24^{\text {th }} \& 25^{\text {th }}$.

Office of national construction regulation. (2012). national construction regulation, article $21^{\text {st }}$ (passive defense) (2nd ed.). Tehran, Tose'eye Iran publication.

Parsons, T. (1937). The Structure of Social Action: A Study in Social Theory with Special Reference to a Group of Recent European Writers. McGraw-Hill Book Company.

Picon, A. (2012). digital terminology in architecture: and introduction for design field of study, translated by Khayatpour Najib M, $1^{\text {st }}$ edition, Parham Naghsh publication.

Schumacher, P. (2009). parametricism - a new global style for architecture and urban design. AD architectural design - digital cities, 79(4). https://doi.org/10.1002/ad.912

Shahraki Moghadam, H., \& Kiani, A. (2013). principles of passive defense with an approach to sustainable architecture in Zabol City, conference of sustainable architecture and urban development, Boukan, May $13^{\text {th }}$.

Shahroudi, A., \& Golabchi, M. (2007). technology \& Architecture: comparative study of the impact of traditional and modern technology on human life and architecture, $1^{\text {st }}$ international conference of structure and architecture, Tehran, April $20^{\text {th }} \& 21^{\text {st }}$.

\section{Copyrights}

Copyright for this article is retained by the author(s), with first publication rights granted to the journal.

This is an open-access article distributed under the terms and conditions of the Creative Commons Attribution license (http://creativecommons.org/licenses/by/4.0/). 